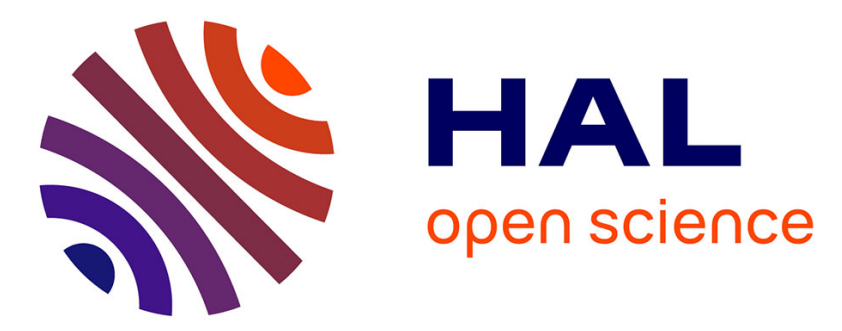

\title{
A new heterogeneous host-guest catalytic system as an eco-friendly approach for the synthesis of cyclic carbonates from $\mathrm{CO} 2$ and epoxides
}

Anaïs Mirabaud, Alexandre Martinez, Francois Bayard, Jean-Pierre Dutasta, Véronique Dufaud

\section{To cite this version:}

Anaïs Mirabaud, Alexandre Martinez, Francois Bayard, Jean-Pierre Dutasta, Véronique Dufaud. A new heterogeneous host-guest catalytic system as an eco-friendly approach for the synthesis of cyclic carbonates from CO 2 and epoxides. New Journal of Chemistry, 2018, 42 (20), pp.16863-16874. 10.1039/C8NJ03065K . hal-02091949

\section{HAL Id: hal-02091949 \\ https://hal.science/hal-02091949}

Submitted on 6 Apr 2019

HAL is a multi-disciplinary open access archive for the deposit and dissemination of scientific research documents, whether they are published or not. The documents may come from teaching and research institutions in France or abroad, or from public or private research centers.
L'archive ouverte pluridisciplinaire HAL, est destinée au dépôt et à la diffusion de documents scientifiques de niveau recherche, publiés ou non, émanant des établissements d'enseignement et de recherche français ou étrangers, des laboratoires publics ou privés. 


\title{
A new heterogeneous host-guest catalytic system as an eco-friendly approach for the synthesis of cyclic carbonates from $\mathrm{CO}_{2}$ and epoxides $\dagger$
}

\author{
Anaïs Mirabaud, ${ }^{a b}$ Alexandre Martinez, (D) ${ }^{c}$ François Bayard, ${ }^{a}$ Jean-Pierre Dutasta*b \\ and Véronique Dufaud (D)*a
}

\begin{abstract}
Two strategies have been explored towards the heterogenization of a host-guest catalytic system where either cavitand host [3iPO] or quaternary ammonium catalysts are grafted on silica supports. The bis-propargyl substituted triphosphonate cavitand [3iPO] was clicked onto an azido functionalized ultra-large pore SBA-15 type silica (UL-SBA-15). Ammonium hybrid materials were produced by grafting a propyltrimethylammonium chloride silane precursor onto silicas of varying porosities and textural properties (UL-SBA-15, SBA-15 and $\mathrm{SiO}_{2}$ ). Extensive characterization of each material is presented (XRD, $N_{2}$ sorption, TGA, solid state NMR, elemental analyses, FT-IR). The effect of heterogenization was investigated in the coupling of $\mathrm{CO}_{2}$ with styrene oxide and was compared to all-soluble cavitand/ammonium homogeneous analogs.
\end{abstract}

\section{Introduction}

Carbon dioxide is an abundant, naturally occurring, non-toxic, low-cost and renewable carbon source. However, its use as a C1 building block in organic transformation to construct more complex molecules has been limited due to its high stability and low reactivity. For these reasons, the catalytic conversion of $\mathrm{CO}_{2}$ to reduce the kinetic barriers while minimizing the overall carbon footprint of the process has recently attracted considerable attention. ${ }^{1-3}$ One of the most successful examples for $\mathrm{CO}_{2}$ fixation is the coupling with epoxides to generate five-membered cyclic carbonates..$^{4-7}$ In addition to their numerous applications as aprotic polar solvents, electrolytes and valuable monomers and intermediates, ${ }^{8-10}$ the production of cyclic carbonates using $\mathrm{CO}_{2}$ as a reagent represents a significant gain in atom economy and process safety over current technologies, i.e. through the elimination of toxic phosgene and/or other corrosive compounds, and as such is highly desirable for industry. ${ }^{11}$ Among the plethora of catalysts developed for this reaction during the last decade, transition metal based complexes used in conjunction with a nucleophile (typically furnished by a quaternary

\footnotetext{
${ }^{a}$ Laboratoire de Chimie, Catalyse, Polymères, Procédés (C2P2), CNRS, Université Claude Bernard Lyon 1, CPE Lyon, 43 Bd du 11 novembre 1918, F-69616 Villeurbanne cedex, France. E-mail:veronique.dufaud@univ-lyon1.fr

${ }^{b}$ Laboratoire de Chimie, École Normale Supérieure de Lyon, CNRS, Université Claude Bernard Lyon 1, 46 allée d'Italie, F-69364 Lyon, France.

E-mail: jean-pierre.dutasta@ens-lyon.fr

${ }^{c}$ Aix Marseille Université, CNRS, Centrale Marseille, iSm2 UMR 7313,

F-13397 Marseille, France
}

ammonium halide salt) occupy a prominent place as they generally show high performance under relatively mild conditions, operating in some cases at room temperature and an atmospheric pressure of $\mathrm{CO}_{2} \cdot{ }^{12-16}$ However, for sustainability considerations and to avoid toxicity issues due to the presence of metallic residues in the final products, metal-free mediated $\mathrm{CO}_{2}$ fixation methodologies have recently attracted attention as alternatives to metal-based technologies. Several structural types of organocatalysts have been shown to enable $\mathrm{CO}_{2}$ fixation into cyclic carbonates such as simple quaternary ammonium and phosphonium salts, ${ }^{17}$ ionic liquids, ${ }^{18,19}$ betain-based structures ${ }^{20}$ and organic bases. ${ }^{21}$ However, most of these require high temperatures and/or pressures to exhibit reasonable activities, significantly compromising the energy balance of the global process. Significant progress in catalyst efficiency was found with the utilization of organic structures bearing $\mathrm{H}$-bonding sites that are able to synergistically activate epoxides and/or stabilize reaction intermediates. ${ }^{2-24}$ Recent examples include the use of binary or bifunctional catalytic systems based on polyphenols, ${ }^{25,26}$ fluorinated alcohols, ${ }^{27}$ silanediols, ${ }^{28}$ amino alcohols ${ }^{29}$ and azaphosphatranes. ${ }^{30-32}$ In all these systems, whether metal-based or organic, activity enhancement relies on the cooperative action of both the Lewis/Brønsted acid activators and the nucleophile at the epoxide through oxygen atom coordination and nucleophilic ring-opening, respectively.

Recently, an alternative approach based on host-guest chemistry has been developed by our group towards ammonium catalyst activation. ${ }^{33}$ In this approach, improved catalytic reactivity was achieved by increasing the nucleophilicity of the halide rather than by enhancing epoxide activation and this relies on the strong binding properties of specifically designed supramolecular 

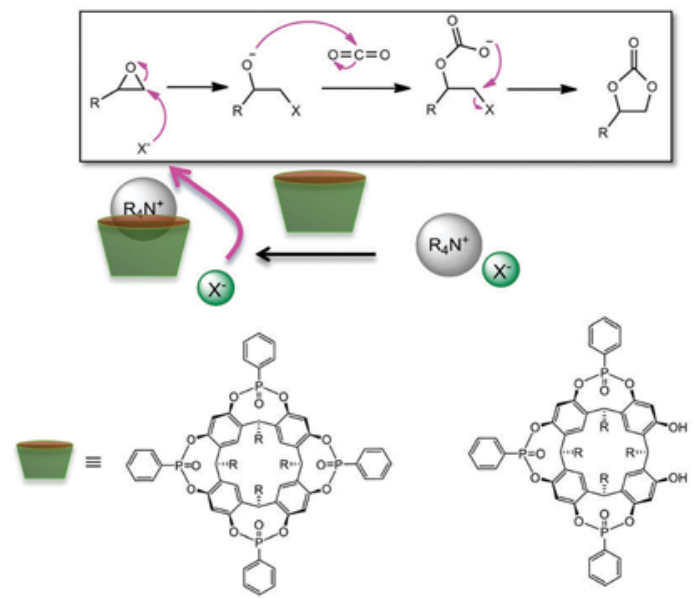

Tetraphosphonate cavitand

Triphosphonate cavitand

Scheme 1 Principle of the host-guest approach to activate the nucleophilicity of the halides of quaternary ammonium salts.

receptors for ammonium recognition. As illustrated in Scheme 1, the use of a phosphonate cavitand host in conjunction with a quaternary ammonium halide results in efficient ion-pair separation, thus activating the anion to perform the initial epoxide ring-opening step.

The potential of this host-guest approach for the coupling of $\mathrm{CO}_{2}$ and epoxide was fully demonstrated in the case of tetramethylammonium halide salts. These were completely inactive when used alone, even at a high temperature and pressure, but the presence of a tetraphosphonate cavitand (Scheme 1, structure on the left) allowed the reaction to proceed efficiently at a low catalyst loading ( $1 \mathrm{~mol} \%$ ) and an atmospheric pressure of $\mathrm{CO}_{2}$. The highest activity, up to $92 \%$ yield of styrene carbonate in $24 \mathrm{~h}$, was obtained with the $\mathrm{Me}_{4} \mathrm{NI} @$ cavitand inclusion complex. ${ }^{33}$ In a subsequent report, the effect of the binding properties as well as the substitution patterns of various cavitand structures on the catalytic performance of tetrabutylammonium halides was explored. ${ }^{34}$ The studies pointed out that the catalytic efficiency of the supramolecular assembly strongly depends on both the structural features and the binding strength of the ammonium/ cavitand association. Thus, triphosphonate cavitand hosts bearing phenolic functions within their structures (Scheme 1, structure on the right) showed outstanding performance (up to 12-fold activity increase in the case of $n-\mathrm{Bu}_{4} \mathrm{NI}$ ) due to the double activation of both the nucleophile (halide) through efficient encapsulation of the ammonium cation and the substrate (epoxide) through hydrogen bonding.

Although homogeneous catalysts generally exhibit high activity and provide an ideal platform for fine-tuning the selectivity of a specific reaction, catalyst separation and product purification are key issues in any modern industrial process. One way to develop more sustainable and economical technologies is to immobilize known active homogeneous catalysts onto insoluble organic or inorganic supports. In this manner, catalyst recovery and recycling are facilitated while maintaining the high efficiency of solution catalysts. Due to its inherent advantages, supported homogeneous catalysis has recently been exploited to provide a wide variety of catalytic hybrid materials, mostly derived from soluble organocatalysts, for the coupling of $\mathrm{CO}_{2}$ with epoxides. The most representative ones include quaternary ammonium and phosphonium salts, ionic liquids, nitrogencontaining bases and aminopyridinium halides supported on either carbon nanotubes, organic polymers, chitosan, polyethylene glycol or inorganic oxides (mainly silica-based oxides). ${ }^{35-43}$ The immobilisation not only facilitated catalyst recovery and recycling, but in certain cases a further beneficial effect on the catalytic performance was reported. For example, Motokura et al. reported that silica supported catalysts based on the 4-pyrrolidinopyridinium iodide motif displayed better catalytic activity than their soluble counterparts in the coupling of $\mathrm{CO}_{2}$ with styrene oxide. According to the authors, this reactivity enhancement could be explained by the presence of $\mathrm{Si}-\mathrm{OH}$ groups on the surface of silica, which could act as weakly acidic sites to synergistically activate the epoxide substrate. ${ }^{36}$ The same observations were independently reported by the groups of $\mathrm{Sakai}^{37}$ and $\mathrm{Takahashi}^{38}$ in the case of silica supported phosphonium halide catalysts. Remarkably, a 300-fold enhancement in the reaction rate was obtained using the immobilized catalyst, $\mathrm{SiO}_{2}-\mathrm{C}_{3} \mathrm{H}_{6}-\mathrm{P}(n-\mathrm{Bu})_{3} \mathrm{I}$, when compared to molecular $\mathrm{P}(n-\mathrm{Bu})_{4} \mathrm{I}$ and an acid-base reaction mechanism was invoked between the organic and inorganic components to account for these results.

We sought to exploit these demonstrated advantages of catalyst immobilisation on weakly acidic supports in the context of our previously mentioned cavitand based host-guest catalytic system. For the design of organic-inorganic hybrid materials, the nature and structural parameters of the host matrix are of crucial importance and can be effectively adapted to the size of the guest molecules. Among the different solid supports available, our choice fell on an unusual type of mesoporous silica of the SBA-15 family characterized by ultra-large pore diameters in the range of 10-12 $\mathrm{nm}$ and channels running along the short axis. ${ }^{44}$ Compared to traditional SBA-15 silica, with its fiber-like morphology of densely packed channels running along the long axis, this engineered cuboid-like silica material has short and open channels that could greatly favour pore accessibility and mass transfer making it particularly suitable as a support to mediate host-guest based transformations.

Concerning the immobilization of the binary catalyst system, we chose to pursue two different strategies as illustrated in Scheme 2. In one, the cavitand host is linked to the oxide support and the quaternary ammonium introduced in solution. Alternatively, the quaternary ammonium salt is covalently attached to the silica support and the cavitand host is introduced under homogeneous conditions.

Herein, we report on the synthesis and characterization of different catalytic systems based on this immobilization strategy and the catalytic performance of these systems in the coupling of styrene oxide with $\mathrm{CO}_{2}$.

\section{Results and discussion}

\section{Covalent immobilization of the cavitand host}

Among the different cavitand architectures developed by our group, the triphosphonate cavitand [3iPO] bearing two propargyl 
groups at the upper rim was selected because it provides both strong binding properties arising from the three $\mathrm{P}=\mathrm{O}$ groups oriented inward with respect to the cavity and the incipient tether to create robust linkages through an azide-alkyne 1,3dipolar cycloaddition ligation process. Our synthetic strategy involves a two-step procedure as shown in Scheme 3. UL-SBA-15 mesoporous silica was first functionalized with 3-azidopropyltriethoxysilane using a post-synthetic grafting method. The resulting hybrid material $\left[\mathbf{N}_{3}\right] / \mathbf{U L}$-SBA-15 was then reacted with cavitand [3iPO] under classical click reaction conditions in the presence of diisopropylethylamine and a catalytic amount of CuI, yielding the hybrid material [3iPO]/UL-SBA-15.

The physicochemical and textural properties of $\left[\mathbf{N}_{3}\right] /$ UL-SBA-15 before and after clicking of [3iPO] are summarized in Table S1 $(\mathrm{ESI} \dagger)$ and small angle powder XRD patterns are displayed in Fig. 1. Four well-resolved Bragg peaks in the $2 \theta$-range of $0.6^{\circ}$ to $2^{\circ}$ indexed to the (100), (110), (200) and (210) reflections were observed for both materials and are indicative of hexagonally ordered mesophases. The presence of higher order reflections as well as the absence of the change of the unit-cell parameters $a_{0}$ with respect to the bare UL-SBA-15 silica (Table S1, ESI $\dagger$ ) indicates that the two-step functionalization process did not impact the long-range and structural ordering of the materials significantly, although a slight decrease in the intensity of the $d_{100}$ reflection was observed for [3iPO]/UL-SBA-15.

Nitrogen adsorption-desorption measurements were used to examine the textural properties of the hybrid materials. The isotherms and pore size distributions are depicted in Fig. 2.

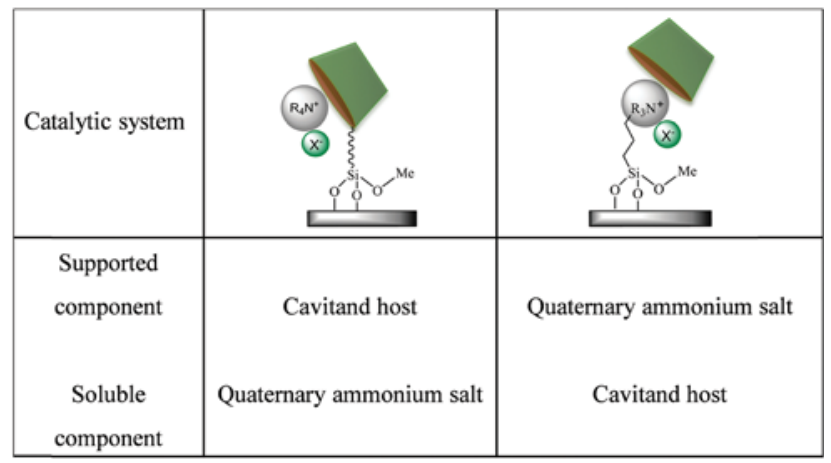

Scheme 2 Configurations of the catalytic systems studied.

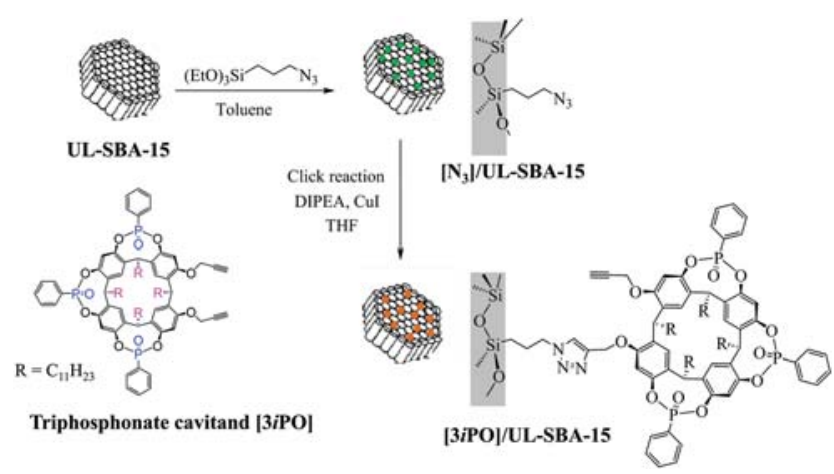

Scheme 3 Immobilization of cavitand [3iPO] through click chemistry.

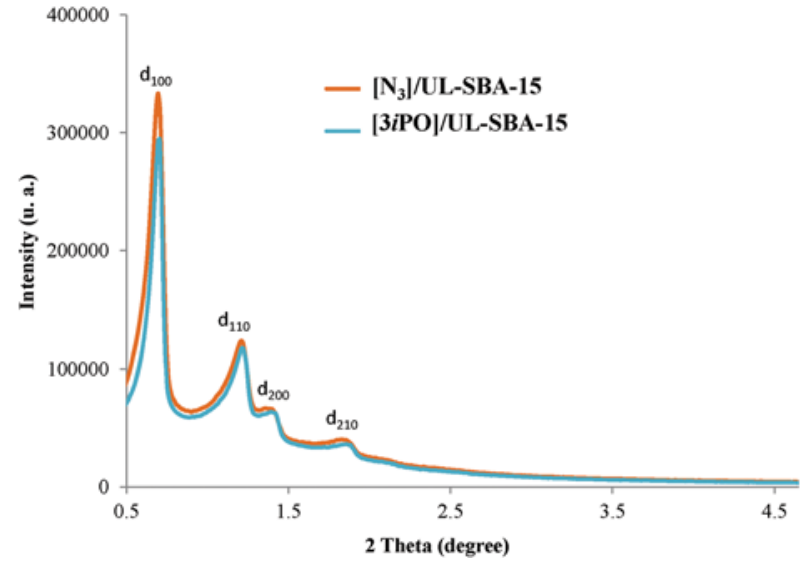

Fig. 1 X-ray powder diffraction patterns of the azide functionalized UL-SBA-15 silica material before and after clicking of cavitand [3iPO].

Both materials exhibited type IV isotherms and H1 hysteresis loop typical of mesoporous solids having cylindrical channels. ${ }^{45}$ The steep capillary condensation step that appeared at $P / P_{0}=$ $0.7-0.9$ (Fig. 2, top) suggests the presence of regular mesopores in the samples, which is in good agreement with the narrow pore size distributions shown in Fig. 2 (bottom). Compared to the parent $\left[\mathbf{N}_{3}\right] / \mathbf{U L}-\mathbf{S B A}-\mathbf{1 5}$, a marked decrease in $\mathbf{N}_{2}$ uptake was observed for [3iPO]/UL-SBA-15, which is consistent with the presence of a bulky cavitand host in the pore channels. The decrease in pore volume (from 1.3 to $0.9 \mathrm{~cm}^{3} \mathrm{~g}^{-1}$, Table S1, ESI $\dagger$ ) was also accompanied by a significant decrease in both surface area (from 508 to $378 \mathrm{~m}^{2} \mathrm{~g}^{-1}$ ) and pore diameter (from 95 to $83 \AA$ ). . Note that since the lattice parameter $a_{0}$ remained unchanged upon clicking of cavitand [3iPO], the decrease in pore diameter resulted in a concomitant increase in the wall thickness from 49 to $61 \AA$ (Table S1, ESI $\dagger$ ), which is also a clear indication of the occupancy of the channels by the cavitand host. This is consistent with the dramatic decrease in surface polarity revealed by the $C_{\mathrm{BET}}$ parameter (from 222 for UL-SBA-15 to 107 for $\left[\mathbf{N}_{3}\right] / \mathbf{U L - S B A - 1 5}$ and 55 for [3iPO]/UL-SBA-15, Table S1, ESI $\dagger$ ). The latter indicates a hydrophobic surface, presumably due to the presence and/or spatial arrangement of the large cavitand molecules on the surface, partially masking the surface silanol functionalities (vide infra).

The successful incorporation of cavitand [3iPO] was assessed by solid-state CP MAS ${ }^{13} \mathrm{C}$ and ${ }^{31} \mathrm{P}$ NMR spectroscopy. Most of the cavitand resonances are discernible in the ${ }^{13} \mathrm{C}$ NMR spectrum of [3iPO]/UL-SBA-15 (Fig. 3), which is indicative that no measurable degradation has occurred during the click process. In particular, one can clearly distinguish the peaks originating from the alkyl chains and those from the aromatic carbons in the spectral regions ranging from 5 to $38 \mathrm{ppm}$ and 102 to $171 \mathrm{ppm}$, respectively (Fig. 3).

In the CP MAS ${ }^{31} \mathrm{P}$ NMR spectrum of [3iPO]/UL-SBA-15 (Fig. 4), one can observe the presence of a relatively broad resonance centered at $12 \mathrm{ppm}$ along with spinning side bands. This chemical shift is coherent with that of cavitand [3iPO] although the width of the signal renders the observation of the inequivalence of the phosphorus atoms impossible as clearly indicated in the liquid ${ }^{31} \mathrm{P}$ spectrum (Fig. S1, ESI $\dagger$ ). 

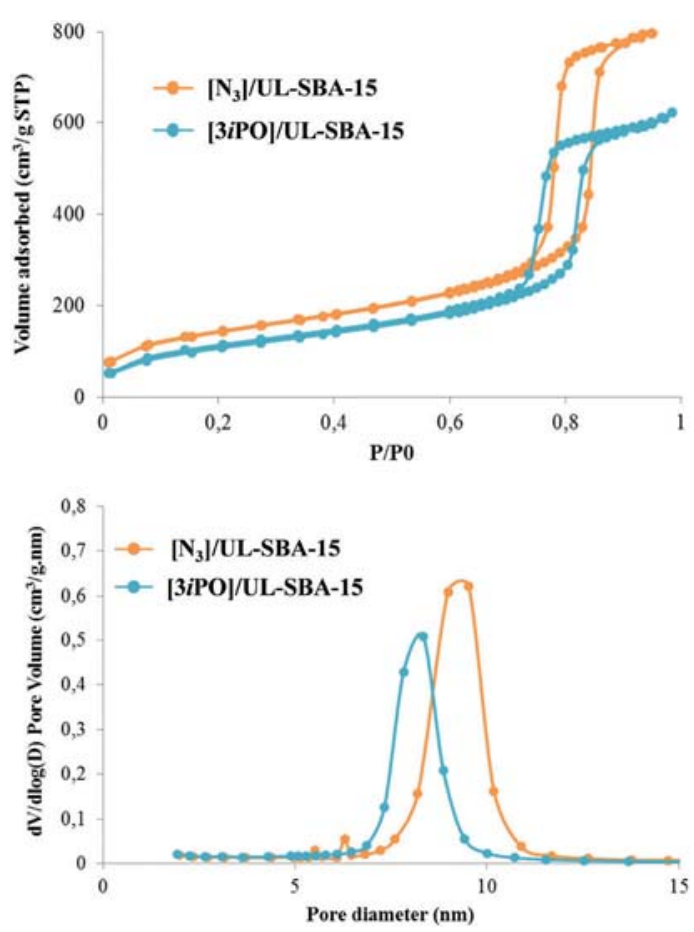

Fig. 2 Nitrogen adsorption-desorption isotherms (top) and pore size distributions (bottom) of the azide functionalized UL-SBA-15 silica material before and after clicking of cavitand [3iPO].

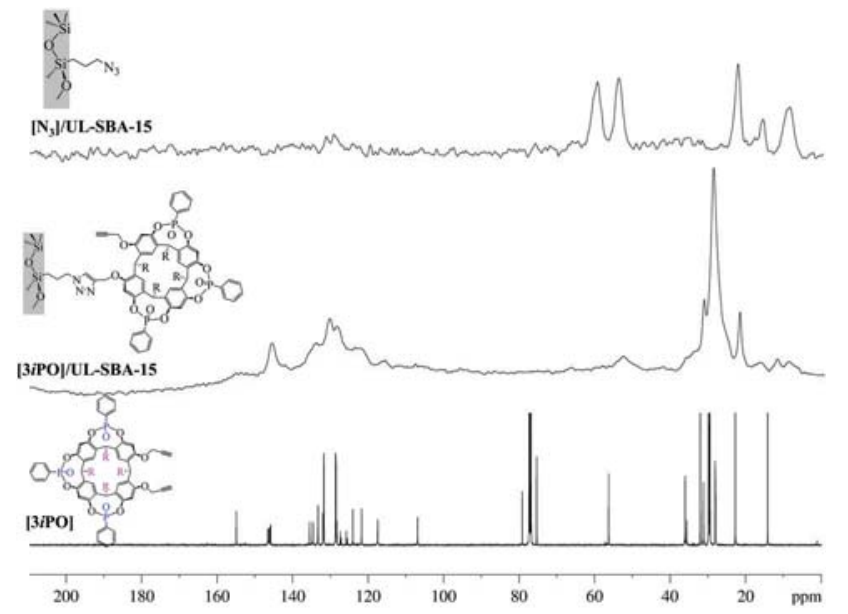

Fig. 3 CP MAS ${ }^{13} \mathrm{C}$ NMR spectra of $\left[\mathrm{N}_{3}\right] /$ UL-SBA-15 and [3iPO]/UL-SBA-15 and liquid ${ }^{13} \mathrm{C}$ NMR spectrum of molecular cavitand [3iPO] for comparison.

Solid-state ${ }^{29} \mathrm{Si}$ NMR provides further information about the silicon environment and the nature of the link to the surface. For both hybrids, $\left[\mathbf{N}_{3}\right] / \mathbf{U L - S B A - 1 5}$ and [3iPO]/UL-SBA-15, the presence of tertiary silicon peaks (T-sites with $\mathrm{T}^{m}=\mathrm{RSi}(\mathrm{OSi})_{m^{-}}$ $\left.(\mathrm{OH})_{3-m}\right)$ around -50 to $-70 \mathrm{ppm}$ confirms the presence of covalently bonded azidopropylsiloxane moieties with different degrees of linkage (Fig. S2, ESI $\dagger$ ). Note that the click conditions appear to facilitate further condensation between unreacted -SiOEt of the azidopropylsiloxane and the silica surface as indicated by the increase in the intensity of the peak at $-70 \mathrm{ppm}\left(\mathrm{T}^{3}\right.$ site $)$.

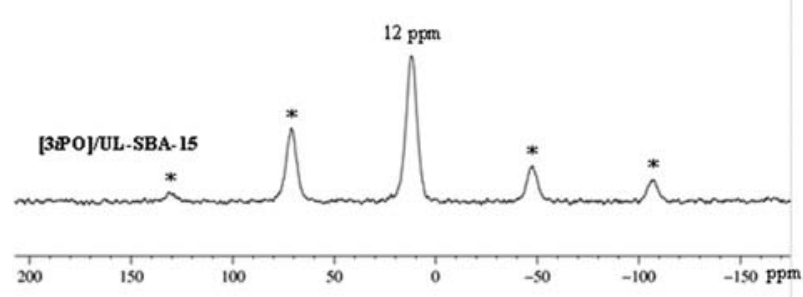

Fig. 4 CP MAS ${ }^{31} \mathrm{P}$ NMR spectrum of [3iPO]/UL-SBA-15. * denotes spinning side bands.

Quantitative determination of organic content in the hybrid materials was performed both by thermogravimetric and elemental analyses and the comparative results are summarized in Table S2 (ESI $\dagger$ ). Thermogravimetric analysis before and after clicking of cavitand [3iPO] was performed under flowing air from room temperature to $900{ }^{\circ} \mathrm{C}$ (Fig. S3, ESI $\dagger$ ). Both materials presented similar patterns composed of two main weight loss regions. The first weight loss occurred at temperatures up to about $130{ }^{\circ} \mathrm{C}$ and was assigned to the desorption of physisorbed water. The second weight loss region between 130 and $600{ }^{\circ} \mathrm{C}$ was ascribed to the decomposition of the organic species and was used to estimate the total organic content. For the purpose of reporting the organic content and provide a meaningful comparison between the material samples, the differences in the water take-up from atmospheric humidity were corrected by considering the $\mathrm{SiO}_{2}$ content of the TGA run at $900{ }^{\circ} \mathrm{C}$. Thus, the azidopropyl loading in $\left[\mathbf{N}_{3}\right] /$ UL-SBA-15 was found to be $0.38 \mathrm{mmol} \mathrm{g}^{-1}$ dry $\mathrm{SiO}_{2}$ and the cavitand amount in [3iPO]/ UL-SBA-15, $0.10 \mathrm{mmol} \mathrm{g}^{-1}$ dry $\mathrm{SiO}_{2}$, was determined by subtracting the total weight loss of [3iPO]/UL-SBA-15 from that of parent $\left[\mathbf{N}_{3}\right] / \mathbf{U L}-\mathbf{S B A}-\mathbf{1 5}$.

Nitrogen and phosphorus elemental analyses also allowed us to perform the quantitative determination of the azidopropyl groups and the cavitand amount in the hybrid materials. These loadings were found to be 0.32 and $0.11 \mathrm{mmol} \mathrm{g}^{-1} \mathrm{dry} \mathrm{SiO}_{2}$ for [N $\left.\mathbf{N}_{3}\right] / \mathbf{U L}-\mathbf{S B A}-15$ and [3iPO]/UL-SBA-15, respectively, which are in good agreement with the TGA data (Table S2, ESI $\dagger$ ). The extent of click found from the elemental analysis was estimated to be $34 \%$ which was further evidenced by FT-IR, notably by the decrease in the intensity of the stretching vibration mode at $2112 \mathrm{~cm}^{-1}$, typical of organic azides (Fig. S4, ESI $\dagger$ ).

\section{Covalent immobilization of the quaternary ammonium guest}

In the immobilized configuration, where the quaternary ammonium salt is covalently attached to the silica support and the cavitand host is introduced in solution, a wider range of silica supports were considered in order to probe other aspects of the catalytic process. In addition to the ultra-large silica used above, we included a series of materials based on a classical SBA-15 silica support and another based on amorphous fumed silica (Degussa), which presents a plane surface. Thus, we can better distinguish, for example, the confinement effects from diffusion considerations, or the issues of active site accessibility $v s$. surface hydrophilicity. The covalent 

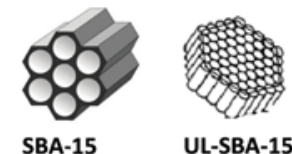

UL-SBA-15

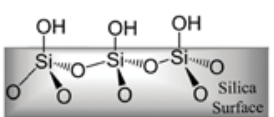

$\mathrm{SiO}_{2}$
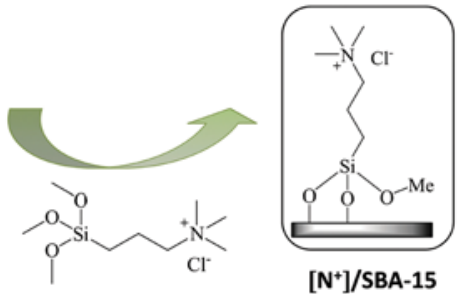

$\left[\mathrm{N}^{+}\right] / \mathrm{SBA}-15$

$\left[\mathrm{N}^{+}\right] /$UL-SBA-15 $\left[\mathrm{N}^{+}\right] / \mathrm{SiO}_{2}$
Scheme 4 Synthetic strategy towards ammonium supported silica materials

immobilization of $N$-[3-(trimethoxysilyl)propyl]- $N, N, N$-trimethylammonium chloride, used as the quaternary ammonium precursor, onto the three silica supports was readily performed by directly reacting the surface silanols with the methoxysilyl groups of the ammonium salt, thus creating robust $\mathrm{Si}-\mathrm{O}-\mathrm{Si}$ siloxane linkages (Scheme 4). Considering the steric encumbrance of the cavitand [4iPO] host targeted for the catalytic studies and to ensure the formation of a 1:1 host-guest complex at the surface of the silica support, an ammonium loading as low as $0.2 \mathrm{mmol} \mathrm{g}^{-1}$ (corresponding to site isolation) was initially considered. Higherloaded ammonium catalysts $\left(\sim 1.2 \mathrm{mmol} \mathrm{g}^{-1}\right)$ were also prepared to study the influence of the site density on the catalyst efficiency.

The state of the solid structure and the integrity of the immobilized ammonium salt were characterized by several methods including X-ray powder diffraction (XRD), nitrogen sorption, elemental analysis, thermogravimetric analysis and multi-nuclei solid state NMR spectroscopy.

The physicochemical and textural properties of the hybrid materials determined from powder XRD and sorption measurements are summarized in Table S3 (ESI $\dagger$ ). Small angle powder XRD patterns of UL-SBA-15 and SBA-15 based materials collected before and after ammonium grafting are displayed in Fig. 5 and Fig. S5 (ESI $\dagger$ ), respectively.

As shown in Fig. 5, all solids based on the UL-SBA-15 silica exhibited diffractograms characteristic of hexagonally ordered mesophases. Four peaks were clearly observed in the $2 \theta$-range of $0.6^{\circ}$ to $2^{\circ}$ assigned to the (100), (110), (200) and (210) reflections, respectively. This suggests that the chemical

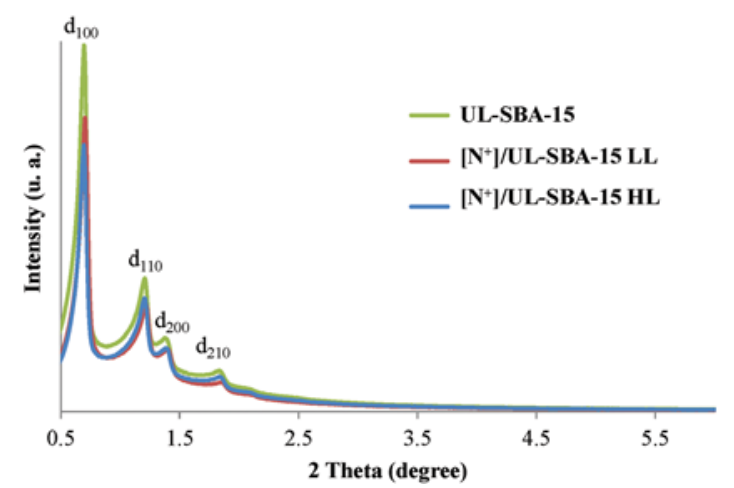

Fig. 5 X-ray powder diffraction patterns of UL-SBA-15 silica before and after grafting $\mathrm{N}$-[3-(trimethoxysilyl)propyl]-N,N,N-trimethylammonium chloride at low (LL) and high (HL) loadings. bonding affected neither the structural ordering of the resulting materials nor the long-range mesostructuration. The most intense peak corresponding to the (100) reflection was located at approximately the same $2 \theta$-value $\left(0.70^{\circ}\right)$ as those obtained for the three solids, thus indicating that the $d$ spacing $(\sim 126 \AA$, Table S3, ESI $\dagger$ ) was nearly unchanged with the loading. However, one can note a decrease in the intensity of the $d_{100}$ reflection upon functionalization, which was more pronounced in the case of the highly-loaded material. This reduction in the diffraction intensity could be attributed to the local disorder and/or to the contrast matching between the amorphous silicate framework and the organic groups located inside the pore channels.

The solids based on SBA-15 also exhibited XRD patterns characteristic of hexagonally ordered mesophases (Fig. S5, ESI $\dagger$ ). In the case of the highly loaded hybrid material, $\left[\mathbf{N}^{+}\right] /$ SBA-15 HL, the intense peak corresponding to the (100) reflection was slightly shifted to a higher $2 \theta$-value compared to that of parent SBA-15 (from $0.87^{\circ}$ to $0.91^{\circ}$ ) with a decrease of the unit-cell parameter $a_{0}$ (from 117 to $112 \AA$, Table S3, ESI $\dagger$ ). This change could result from a small contraction of the pore volume due to the immobilization of a larger amount of ammonium groups in the channels.

Nitrogen adsorption-desorption measurements were used to examine the textural properties of the hybrid materials. Typical isotherms and pore size distributions of the UL-SBA-15 based solids are depicted in Fig. 6 . The isotherms and pore size distributions of the SBA-15 and $\mathrm{SiO}_{2}$ derived materials are displayed in Fig. S6 and S7 (ESI $\dagger$ ), respectively.
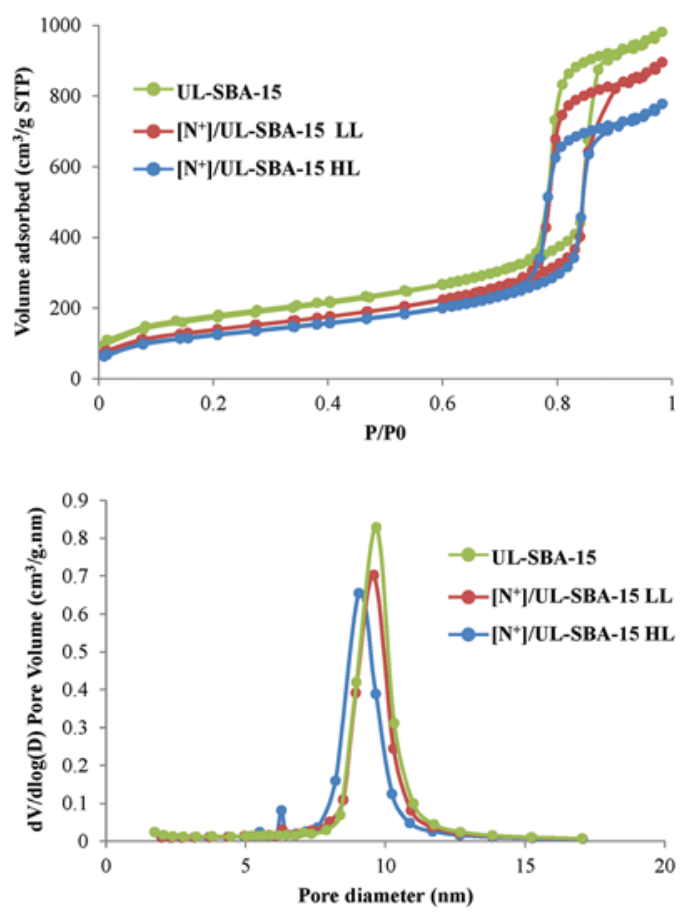

Fig. 6 Nitrogen adsorption-desorption isotherms (top) and pore size distributions (bottom) of the ammonium functionalized UL-SBA-15 silica materials and parent UL-SBA-15. 
All the solids based on UL-SBA-15 and SBA-15 silicas showed type IV isotherms and $\mathrm{H} 1$ hysteresis loop characteristic of mesoporous solids. In the case of SBA-15 derived materials, the steep capillary condensation step appeared at a lower relative pressure $\left(P / P_{0}=0.6-0.8\right)$ than for the corresponding UL-SBA-15 solids $\left(P / P_{0}=0.7-0.9\right)$, which is in total agreement with the change in the mean pore diameters.

For both types of materials, a marked decrease in the BET surface areas and pore volumes was observed upon functionalization, whereas the pore diameters and wall thicknesses were only affected when the ammonium content was increased (Table S3, ESI $\dagger$ ). Taken together, these results are consistent with the presence of ammonium species attached to the internal surface of the mesopores. In the case of non-porous $\mathrm{SiO}_{2}$ based materials, the adsorption-desorption isotherms (Fig. S7, ESI $\dagger$ ) were of type III (IUPAC classification). ${ }^{45}$ The absence of hysteresis confirmed that the materials were not porous. Furthermore, the BET surface areas were found to be much lower (201-166 $\left.\mathrm{m}^{2} \mathrm{~g}^{-1}\right)$ than those of the SBA-15 (916-492 $\mathrm{m}^{2} \mathrm{~g}^{-1}$ ) and UL-SBA-15 (618-437 $\mathrm{m}^{2} \mathrm{~g}^{-1}$ ) based materials (Table S3, ESI $\dagger$ ), which, at equivalent loading, may impact the site density and hence the catalytic reactivity (vide infra).

The integrity and covalent anchoring of quaternary ammonium fragments for all hybrid materials were assessed by CP-MAS ${ }^{13} \mathrm{C}$ and ${ }^{29} \mathrm{Si}$ NMR, respectively. Fig. 7 shows the ${ }^{13} \mathrm{C}$ NMR spectra of the UL-SBA-15 derived materials, at low and high loading, together with the liquid ${ }^{13} \mathrm{C}$ NMR spectrum of the propyltrimethylammonium chloride precursor. ${ }^{13} \mathrm{C}$ NMR data for the hybrid materials based on SBA-15 and non-porous $\mathrm{SiO}_{2}$ are displayed in Fig. S8 and S9 (ESI $\dagger$ ), respectively. In all the cases, one can clearly see that the integrity of the organic fragments was maintained throughout the grafting and subsequent workup as evidenced by the presence of, as resolvable peaks, all the characteristic resonances of the corresponding molecular precursor.

Solid state ${ }^{29} \mathrm{Si}$ NMR spectroscopy provides further information about the nature of the link to the surface. As shown in Fig. 8, the ${ }^{29} \mathrm{Si}$ CP MAS NMR spectra of the UL-SBA-15 based materials after grafting displayed discernible peaks in two different spectral regions: one region ranging from -90 to $-120 \mathrm{ppm}$, characteristic of Q-type $\left(\mathrm{Q}^{n}=\mathrm{Si}-(\mathrm{OSi})_{n}-(\mathrm{OH})_{4-n}\right)$ silicates originating from the siliceous bulk material and

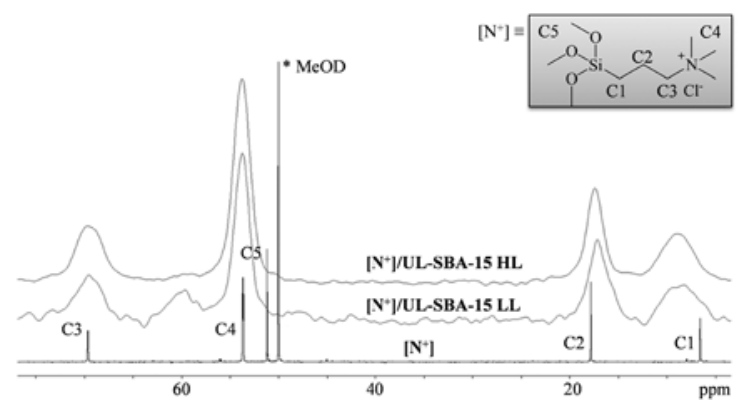

Fig. 7 CP MAS ${ }^{13} \mathrm{C}$ NMR spectra of the ammonium hybrid materials based on UL-SBA-15 silica and liquid ${ }^{13} \mathrm{C}$ NMR spectrum of the molecular $\mathrm{N}$-[3(trimethoxysilyl)propyl]-N,N,N-trimethylammonium chloride precursor.

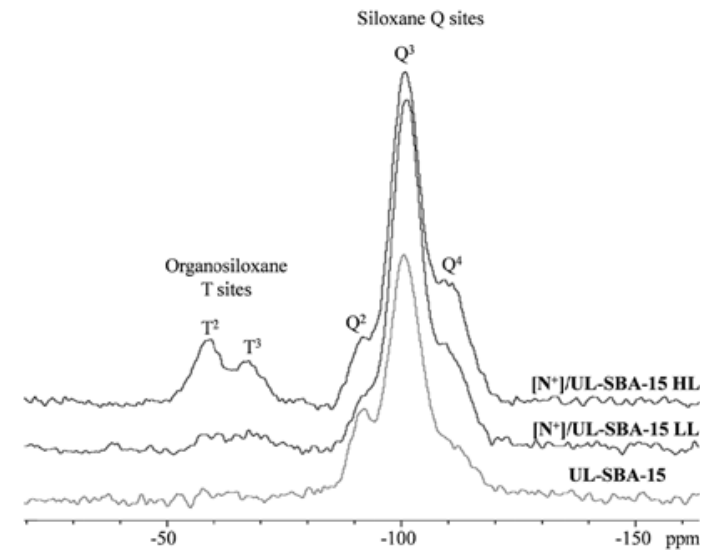

Fig. 8 CP MAS ${ }^{29}$ Si NMR spectra of the ammonium hybrid materials based on UL-SBA-15 silica and of native UL-SBA-15.

another set of signals appearing in the -50 to $-80 \mathrm{ppm}$ spectral region ascribed to T-type $\left(\mathrm{T}^{m}=\mathrm{RSi}-(\mathrm{OSi})_{m}-(\mathrm{OH})_{3-m}\right)$ silicates, that is, the silicon atoms attached to the ammoniumpropyl chain, which is a clear indication of covalent bonding. Similar ${ }^{29}$ Si NMR patterns were observed for the hybrid materials based on SBA-15 and non-porous $\mathrm{SiO}_{2}$ (Fig. S10 and S11, ESI $\dagger$ respectively). Note that multiple peaks were obtained from each of the modified oxides, notably at high ammonium loadings, which suggests different degrees of linkage of the ammoniumsiloxane groups with the silica surface.

Quantitative determination of ammonium content in the hybrid materials was performed by nitrogen and chlorine elemental analysis and thermogravimetric analysis in air. The results are summarized in Table 1 . The elemental analysis data are derived from the raw $\%_{\mathrm{wt}} \mathrm{N}$ (Table S4, ESI $\dagger$ ) compared to the dry weight of the material (indicated by the TGA determination of the residual mass at $900{ }^{\circ} \mathrm{C}$, Table S5, ESI $\dagger$ ). The derivation of loading using only TGA measurements is based on the comparison of the mass loss in the 130 to $600{ }^{\circ} \mathrm{C}$ zone to the silica dry weight (Fig. S12-S14 and Table S5, ESI $\dagger$ ) and assuming that, on average, the grafted species are linked by two siloxane bonds to the surface. Evidence for the latter assumption is indicated by the presence of $\mathrm{T}^{1}$ and $\mathrm{T}^{2}$ sites in the ${ }^{29} \mathrm{Si}$ NMR spectra. With one exception, the two values were consistent within the experimental error as shown in Table 1.

For the low-loaded materials, we determined a similar ammonium content to that introduced $\left(0.24 \mathrm{mmol} \mathrm{g}^{-1}\right.$ dry $\left.\mathrm{SiO}_{2}\right)$,

Table 1 Comparison of the quantitative data derived from elemental analysis and TGA measurements

\begin{tabular}{|c|c|c|c|}
\hline \multirow[b]{2}{*}{ Materials } & \multirow[b]{2}{*}{$\begin{array}{l}\text { TGA } \\
\left(\mathrm{mmol} \mathrm{g}^{-1} \text { dry } \mathrm{SiO}_{2}\right)\end{array}$} & \multicolumn{2}{|c|}{ Elemental analysis } \\
\hline & & $\begin{array}{l}\left(\mathrm{mmol} \mathrm{g}^{-1}\right. \\
\left.\text { dry } \mathrm{SiO}_{2}\right)\end{array}$ & $\mathrm{Cl} / \mathrm{N}^{a}$ \\
\hline$\left[\mathbf{N}^{+}\right] /$SBA-15 LL & $0.44 \pm 0.10$ & $0.24 \pm 0.03$ & $0.79 \pm 0.16$ \\
\hline$\left[\mathbf{N}^{+}\right] /$SBA-15 HL & $1.02 \pm 0.16$ & $1.20 \pm 0.13$ & $0.80 \pm 0.16$ \\
\hline$\left[\mathbf{N}^{+}\right] /$UL-SBA-15 LL & $0.29 \pm 0.08$ & $0.24 \pm 0.03$ & $0.75 \pm 0.15$ \\
\hline$\left[\mathrm{N}^{+}\right] /$UL-SBA-15 HL & $0.68 \pm 0.12$ & $0.52 \pm 0.06$ & $1.13 \pm 0.23$ \\
\hline$\left[\mathbf{N}^{+}\right] / \mathrm{SiO}_{2} \mathbf{L L}$ & $0.24 \pm 0.07$ & $0.25 \pm 0.03$ & $0.88 \pm 0.18$ \\
\hline$\left[\mathrm{N}^{+}\right] / \mathrm{SiO}_{2} \mathbf{H L}$ & $0.32 \pm 0.08$ & $0.39 \pm 0.04$ & $0.82 \pm 0.16$ \\
\hline
\end{tabular}

${ }^{a}$ Molar ratio. 
whereas in the case of the highly loaded materials, the ammonium content was found, in certain cases, to be notably lower than the

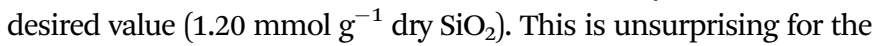

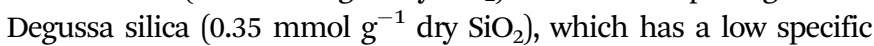
surface area $\left(200 \mathrm{~m}^{2} \mathrm{~g}^{-1}\right)$, where the steric saturation of the surface can be a limiting factor. In the case of the UL-SBA-15 support $\left(620 \mathrm{~m}^{2} \mathrm{~g}^{-1}\right)$, where we determined approximately $0.60 \mathrm{mmol} \mathrm{g}^{-1}$ dry $\mathrm{SiO}_{2}$, the lower loading may be due to the unusual morphology of this material exhibiting cuboid-like structure with channels running along the short axis.

Note that the $\mathrm{Cl} / \mathrm{N}$ molar ratio of the grafted species was found to be on average $0.85 \pm 0.15$, which suggests that the stoichiometry of the ammonium molecular precursor was not affected by the grafting procedure.

\section{Coupling of $\mathrm{CO}_{2}$ and epoxides to cyclic carbonates}

The influence of the heterogenization of either cavitand or quaternary ammonium on the catalytic performance was investigated in detail using styrene oxide as the model substrate under standard reaction conditions $\left(80{ }^{\circ} \mathrm{C}, 10\right.$ bar of $\mathrm{CO}_{2}, 2 \mathrm{~mol} \%$ of a binary catalyst having a 1:1 molar ratio in methylethyl ketone (MEK) solvent). All yields reported below are at 18 hours of reaction. The heterogeneous catalytic reaction results were compared for each case to the corresponding all-soluble binary host-guest homogeneous catalyst systems.

Supported cavitand/soluble ammonium host-guest configuration. In the case where the cavitand host [3iPO] was immobilized onto the UL-SBA-15 silica, tetrabutylammonium iodide was chosen as the soluble catalyst counterpart owing to its excellent performance in the coupling of $\mathrm{CO}_{2}$ and epoxides when combined with the triphosphonate cavitand. ${ }^{34}$ The catalytic results are summarized in Table 2 . First, the ammonium catalyst, $n$ - $\mathrm{Bu}_{4} \mathrm{NI}$, was tested alone under homogeneous conditions, showing a moderate reactivity with a yield of $20 \%$ of styrene carbonate produced (Table 2, entry 1). As expected, the addition of 1 equivalent of cavitand [3iPO] to the reaction mixture led to a marked increase in activity, producing a $55 \%$ yield (Table 2, entry 2). Since beneficial effects have already been reported in the case of silica-based materials, ${ }^{36-38}$ a control experiment using the native UL-SBA-15 silica was carried out in order to evaluate the intrinsic contribution of the support itself to the overall activity. Surprisingly, a dramatic activity enhancement,

Table 2 Influence of cavitand immobilization on the coupling of $\mathrm{CO}_{2}$ with styrene oxide catalysed by $n-\mathrm{Bu}_{4} \mathrm{NI}$

\begin{tabular}{lll}
\hline Entry & Co-catalyst & Yield (\%) \\
\hline 1 & - & 20 \\
2 & {$[3 i$ PO] } & 55 \\
3 & Native UL-SBA-15 & 78 \\
4 & {$\left[3 i\right.$ PO] $/$ UL-SBA-15 $^{a}$} & 45 \\
5 & {$\left[\mathbf{N}_{3}\right] / \mathbf{U L S B A}^{a} \mathbf{S 5}^{a}$} & 60
\end{tabular}

Conditions: styrene oxide ( $2 \mathrm{mmol}), n$-Bu $\mathrm{Bu}_{4} \mathrm{NI}$ catalyst $(2 \mathrm{~mol} \%)$, cavitand (grafted or soluble, $2 \mathrm{~mol} \%$ ), solvent MEK $(6 \mathrm{~mL}), 80{ }^{\circ} \mathrm{C}, 10 \mathrm{bar}$ of $\mathrm{CO}_{2}$ and 18 hours. Yields were determined by ${ }^{1} \mathrm{H}$ NMR using 2,4-dibromomesitylene $(0.4 \mathrm{mmol})$ as an internal standard. ${ }^{a}$ Mass introduced and loadings are given in Table S6 (ESI). greater than was expected, was obtained achieving a yield as high as $\mathbf{7 8 \%}$ (Table 2, entry 3 ). Note that the UL-SBA-15 silica alone is totally inactive. This remarkable result could be explained by a high density of the surface silanols on the UL-SBA-15 support in accordance with a $C_{\mathrm{BET}}$ value of 222 determined from the nitrogen sorption measurements (Table S1, ESI $\dagger$ ) and indicative of a very hydrophilic surface. The association of $n$ - $\mathrm{Bu}_{4} \mathrm{NI}$ with [3iPO]/UL-SBA-15 gave rise to a more modest yield improvement with $45 \%$ of styrene carbonate (Table 2, entry 4 ). This increase in activity with respect to $n-\mathrm{Bu}_{4} \mathrm{NI}$ used alone was comparable to that obtained with soluble [3iPO] but much lower than that obtained with the native UL-SBA-15 silica. This could be due to a lower concentration of silanols available on the surface of [3iPO]/UL-SBA-15 as evidenced by a $C_{\mathrm{BET}}$ parameter value of 55 characteristic of very hydrophobic surfaces (Table S1, ESI $\dagger$ ). Recall that prior to clicking the cavitand [3iPO] a fraction of the surface silanols of UL-SBA-15 had already been consumed in the reaction with 3-azidopropyltriethoxysilane during the pre-functionalization step. To test this hypothesis and further demonstrate the correlation between the catalytic activity and the surface polarity, the reactivity of $n-\mathrm{Bu}_{4} \mathrm{NI}$ was evaluated in the presence of the parent $\left[\mathbf{N}_{3}\right] / \mathbf{U L}$ SBA-15 hybrid material characterized by a $C_{\text {BET }}$ parameter of 107 (Table S1, ESI $\dagger$ ). As shown in Table 2 (entry 5), a yield of $60 \%$ was achieved after $18 \mathrm{~h}$ of reaction, an activity intermediate between that obtained with the native UL-SBA-15 silica and [3iPO]/UL-SBA-15.

Further information regarding the spatial arrangement of the cavitand molecules as well as the azidopropyl groups on the surface was provided by molecular mechanic simulation using the crystalline structure of $\beta$-cristobalite as a model of hydroxylated silica (see the Experimental section). Fig. 9 shows a top view of a surface containing cavitand [3iPO] and the azidopropyl functions with site densities identical to those determined for [3iPO]/UL-SBA-15.

One can clearly notice a stacking of the long C11 alkyl chains of the cavitand [3iPO] along the surface of the material due to weak interactions with the surface functionalities. Thus, after the pre-functionalization step, the residual silanols may be

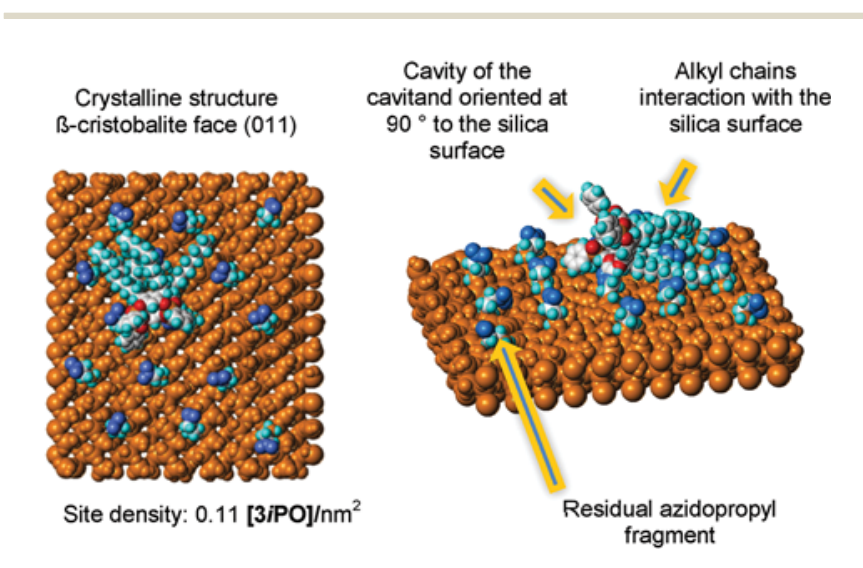

Fig. 9 Modelling of the surface functional groups present in [3iPO]/ULSBA-15. Color assignment: silica surface in brown, nitrogen atoms in darkblue, carbon atoms in white, hydrogen atoms in light-blue and oxygen atoms in red. 
partially obscured by the introduction of the cavitand molecules. As shown in the view on the right, the cavity of [3iPO] is oriented at $90^{\circ}$ to the surface of the material. This suggests that the cavity is accessible to the ammonium cations. Also note that the large cavitand molecules are quite isolated on the surface with a site density of $0.10[3 i \mathrm{PO}] / \mathrm{nm}^{2}$, which should not affect the diffusion of the quaternary ammonium and the epoxide molecules within the material.

Taken together, it seems that the lower activity observed with [3iPO]/UL-SBA-15 is more likely due to a lower concentration of the $\mathrm{Si}-\mathrm{OH}$ groups surrounding the cavitand than to diffusional constraints, thus suppressing any cooperative action "cavitand/ $\mathrm{Si}-\mathrm{OH}$ group" for an optimized activation of the epoxide substrate.

Soluble cavitand/supported ammonium host-guest configuration. In this series of experiments, butyl-trimethylammonium chloride was selected due to its close structural similarity to the grafted ammonium molecular fragments as the soluble analogue of the heterogeneous catalysts. All the ammonium-based hybrid materials prepared above were systematically tested to explore the effects that the textural and structural properties of the silica matrix as well as ammonium loading might have on the overall catalytic performance. For the runs in the presence of soluble hosts, the tetraphosphonate cavitand [4iPO], which bears short propyl chains at the lower rim, was chosen due to its remarkable affinity towards ammonium cations as we have previously reported. ${ }^{33}$

Catalytic reactivity was first examined in the absence of any cavitand co-catalyst. As shown in Table 3, entry 1, the reaction with $\mathrm{BuMe}_{3} \mathrm{NCl}$ proceeds with modest activity, yielding $11 \%$ styrene carbonate. In the case of the low loaded hybrid materials (Table 3, entries 2-4), a marked difference in activity was observed among these catalysts having a similar ammonium loading $\left(\sim 0.25 \mathrm{mmol}\left[\mathrm{N}^{+}\right]\right.$per $\mathrm{g}$ dry silica). The mesoporous based materials $\left[\mathbf{N}^{+}\right] /$SBA-15 LL and $\left[\mathbf{N}^{+}\right] /$UL-SBA-15 LL both displayed very low yields, 4 and $6 \%$, respectively, whereas a yield of $41 \%$ was achieved with the material derived from the non-porous silica $\left[\mathbf{N}^{+}\right] / \mathbf{S i O}_{2}$ LL. Note that the latter catalyst exhibits the highest ammonium density $\left(0.75\left[\mathrm{~N}^{+}\right] / \mathrm{nm}^{2}\right)$ due to its significantly lower specific surface $\left(200 \mathrm{~m}^{2} \mathrm{~g}^{-1}\right.$ against
$618 \mathrm{~m}^{2} \mathrm{~g}^{-1}$ and $916 \mathrm{~m}^{2} \mathrm{~g}^{-1}$, Table S3, ESI $\left.\dagger\right)$. Thus, the high ammonium coverage of the surface appears to be beneficial for the reactivity. This was unexpected considering that a high coverage necessarily implies a low silanol concentration, depriving the reaction of a key element in the activation of the epoxide substrate.

In all the cases, one can also observe that the increase of ammonium loading led to an improved catalytic activity with yields ranging from 27 to $46 \%$ (Table 3, entries 5-7).

Again, the best performance was obtained with the $\mathrm{SiO}_{2}$ based hybrid material $\left[\mathbf{N}^{+}\right] / \mathbf{S i O}_{2} \mathbf{H L}$, which also presented the highest site density $\left(1.17 \mathrm{mmol}\left[\mathrm{N}^{+}\right]\right.$per $\mathrm{g}$ dry silica), thus confirming that the site density is a crucial parameter to consider to achieve a greater reactivity. Finally, regardless of the identity of the support, if the ammonium density is sufficiently high (over $0.51 \mathrm{mmol}\left[\mathrm{N}^{+}\right]$per $\mathrm{g}$ dry silica), the supported ammonium catalysts proved to be more active than their homogeneous homologue $\mathrm{BuMe}_{3} \mathrm{NCl}$ with yields 2.5 to 4 times higher.

The effect of the addition of the cavitand host [4iPO] to these immobilized ammonium catalysts was then examined. As expected, under homogeneous conditions, the association of $\mathrm{BuMe}_{3} \mathrm{NCl}$ with [4iPO] had a strong effect on the catalysis, resulting in a 4-fold yield increase (Table 3, compare entries 1 and 8). In the case of the immobilized ammonium catalysts, however, a dramatic decrease in activity was observed upon addition of [4iPO], the strongest effects being obtained for the $\left[\mathbf{N}^{+}\right] / \mathbf{U L}-\mathbf{S B A}-\mathbf{1 5} \mathbf{~ H L}$ and $\left[\mathbf{N}^{+}\right] / \mathbf{S i O}_{2} \mathbf{~ L L}$ hybrid materials, where co-catalyst addition led to a 8 and 6.5 -fold drop in the yields, respectively (Table 3, compare entries 6 and 11 and entries 4 and 10).

Several hypotheses could be put forth to tentatively explain the inhibiting effect of [4iPO] on the reactivity of the supported ammonium catalysts. For example, the steric encumbrance of the cavitand, whose cavity diameter is on average $2 \mathrm{~nm}$, could result in clogging of the pore channels of the mesoporous materials. However, this hypothesis does not account for similar results obtained with the low loaded catalyst $\left[\mathbf{N}^{+}\right] / \mathbf{S i O}_{2} \mathbf{L L}$, which, despite a plane surface, also showed a marked decrease in yield when associated with [4iPO]. Another hypothesis would be that the cavitand, when complexing the grafted quaternary

Table 3 Influence of ammonium immobilization on the coupling of $\mathrm{CO}_{2}$ with styrene oxide in the presence or absence of cavitand [4iPO]

\begin{tabular}{|c|c|c|c|c|c|}
\hline Entry & Catalyst & Co-catalyst & Loading (mmol $\left[\mathrm{N}^{+}\right]$per $\mathrm{g}$ dry silica) & Site density $\left(\left[\mathrm{N}^{+}\right]\right.$per $\left.\mathrm{nm}^{2}\right)$ & Yield $(\%)$ \\
\hline 1 & $\mathrm{BuMe}_{3} \mathrm{NCl}$ & - & - & - & 11 \\
\hline 2 & {$\left[\mathrm{~N}^{+}\right] /$SBA-15 LL } & - & 0.24 & 0.16 & 4 \\
\hline 3 & {$\left[\mathbf{N}^{+}\right] /$UL-SBA-15 LL } & - & 0.24 & 0.23 & 6 \\
\hline 4 & {$\left[\mathbf{N}^{+}\right] / \mathrm{SiO}_{2} \mathbf{L L}$} & - & 0.25 & 0.75 & 41 \\
\hline 5 & {$\left[\mathbf{N}^{+}\right] /$SBA-15 HL } & - & 1.20 & 0.79 & 27 \\
\hline 6 & {$\left[\mathbf{N}^{+}\right] / \mathbf{U L}-\mathrm{SBA}-15$ HL } & - & 0.52 & 0.51 & 39 \\
\hline 7 & {$\left[\mathbf{N}^{+}\right] / \mathrm{SiO}_{2} \mathbf{H L}$} & - & 0.39 & 1.17 & 46 \\
\hline 8 & $\mathrm{BuMe}_{3} \mathrm{NCl}$ & [4iPO] & - & - & 45 \\
\hline 9 & {$\left[\mathbf{N}^{+}\right] / \mathbf{U L}-\mathbf{S B A}-15 \mathbf{L L}$} & [4iPO] & 0.24 & 0.23 & 0 \\
\hline 10 & {$\left[\mathbf{N}^{+}\right] / \mathbf{S i O}_{2} \mathbf{L L}$} & [4iPO] & 0.25 & 0.75 & 5 \\
\hline 11 & {$\left[\mathbf{N}^{+}\right] /$UL-SBA-15 HL } & [4iPo] & 0.52 & 0.51 & 6 \\
\hline 12 & {$\left[\mathbf{N}^{+}\right] / \mathrm{SiO}_{2} \mathbf{H L}$} & [4iPO] & 0.39 & 1.17 & 30 \\
\hline
\end{tabular}

Conditions: styrene oxide ( $2 \mathrm{mmol})$, ammonium catalyst (grafted or soluble, $2 \mathrm{~mol} \%)$, cavitand co-catalyst $(2 \mathrm{~mol} \%)$, solvent $\mathrm{MEK}(6 \mathrm{~mL}), 80{ }^{\circ} \mathrm{C}$, 10 bar of $\mathrm{CO}_{2}$ and $18 \mathrm{~h}$. Yields were determined by ${ }^{1} \mathrm{H}$ NMR using 2,4-dibromomesitylene (0.4 mmol) as an internal standard. In the case of the hybrid materials, mass introduced and loadings are given in Tables S7 and S8 (ESI). 


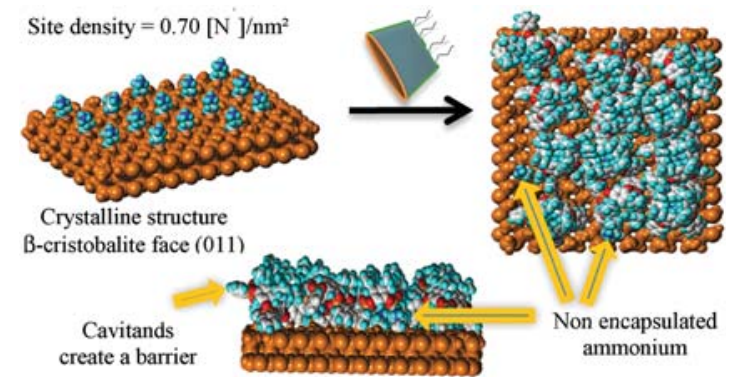

Fig. 10 Molecular modelling of the positioning of cavitand [4iPO] above a silica surface functionalized with propyltrimethylammonium chloride fragments. Color assignment: silica surface in brown, nitrogen atoms in dark-blue, carbon atoms in white, hydrogen atoms in light blue and oxygen atoms in red.

ammonium salts, creates a barrier preventing the epoxide from getting closer to the surface where the chloride anion is located.

To test this hypothesis, a series of molecular mechanics simulations was performed using the crystalline structure of $\beta$-cristobalite as a model of hydroxylated silica as explained earlier. Fig. 10 (left) shows a top view of a surface containing propyltrimethylammonium chloride fragments with a site density of $0.70 \mathrm{mmol}\left[\mathrm{N}^{+}\right]$per $\mathrm{nm}^{2}$ close to that of the $\left[\mathrm{N}^{+}\right] / \mathbf{S i O}_{2} \mathbf{L L}$ hybrid material. Fig. 10 (right and middle) shows the top and side views of cavitand [4iPO] encapsulating the ammonium cations. One can observe the presence of the remaining free ammonium cations, suggesting that the formation of a $1: 1$ host-guest complex on the surface was only partially achieved at this ammonium coverage likely due to the bulkiness of the cavitand hosts. Furthermore, the lateral view of the hybrid material seemed to show that the cavitand hosts, while encapsulating the ammonium cation, do indeed constitute a barrier between the surface of the support and the reaction medium, perhaps capable of preventing or at least disfavoring the approach of the epoxide to the chloride anion, that is slowing the key epoxide ring-opening step of the catalytic cycle. This could account for the lack of activity of the immobilized ammonium catalysts in the presence of cavitand [4iPO].

\section{Conclusions}

In the present study, the heterogenization of the host-guest catalytic system based on phosphonate cavitand/ammonium supramolecular assemblies has been achieved through the immobilization of either the cavitand host or the quaternary ammonium guest onto an unusual type of SBA-15 mesoporous silica (UL-SBA-15) characterized by ultra-large pore diameters and short channels and particularly well-suited to mediate host-guest transformations. In the first case, the triphosphonate cavitand [3iPO] substituted with propargyl moieties was covalently attached via click chemistry to the UL-SBA-15 support containing azidopropyl fragments. In the case of ammonium-based hybrid materials bearing propyltrimethylammonium chloride surface functionalities, a series of materials was prepared by varying the ammonium content and the nature of the silica support to further probe the effects of the site density, diffusion pathways and confinement effects. The new hybrid materials were fully characterized using a wide range of analytical and spectroscopic techniques to attest the structural ordering and textural properties of the solid as well as the integrity and molecular state of the organic inclusions. The catalytic performances of the two host-guest systems were investigated in the coupling of $\mathrm{CO}_{2}$ with styrene oxide as the model substrate. In both systems, a modification of the catalytic properties was observed, evidencing the interaction between the cavitand host and the quaternary ammonium heads. Nevertheless, the two models behaved quite differently. In the case of the cavitand host grafted on the UL-SBA-15 silica, the yield was found to be comparable to that obtained under homogeneous conditions with the all-soluble $n$ - $\mathrm{Bu}_{4} \mathrm{NI} /[3 i \mathbf{P O}]$ catalyst system and two-fold higher than in the reaction with $n$ - $\mathrm{Bu}_{4} \mathrm{NI}$ alone. In this case, we could observe a positive effect attributed to the enhanced nucleophilicity of the iodide anion. However, native UL-SBA-15 in the presence of ammonium was still more efficient, highlighting the strong effect of the silica surface silanols on the overall performance. In contrast, the ammonium-grafted materials without a cavitand afforded fairly good yields of styrene carbonate, whereas a strong deactivation occurred when the same catalysts were combined with soluble [4iPO], regardless of the type of silica support. The dramatic decrease in carbonate yields was attributed to the strong binding ability of the cavitand for the grafted ammonium guests, leading to the covering of the catalytic surface by the host and the isolation, even partially, of the nucleophile from the incoming epoxide. These results were strongly supported by modelling the different functional surfaces using molecular mechanics simulations.

\section{Experimental section}

\section{General}

Commercial reagents were purchased from Aldrich Chemical, Alfa-Aesar or ABCR and used without further purification unless otherwise noted. Solvents were dried using standard methods and stored over activated $4 \AA$ molecular sieves. $\mathrm{CO}_{2}$ of a purity of 99.99\% was commercially obtained and used without further purification. (3-Iodopropyl)triethoxysilane was prepared by reacting (3-chloropropyl)triethoxysilane with $\mathrm{NaI}$ in refluxing acetone for $72 \mathrm{~h}$ according to the method described by Matsura et $a .^{46}$. (3-Azidopropyl)triethoxysilane was synthesized by reacting (3-iodopropyl)triethoxysilane with an excess of sodium azide (5 eq.) in dry DMF at $50{ }^{\circ} \mathrm{C}$ for $72 \mathrm{~h}$ by adapting a procedure described elsewhere. ${ }^{47}$ The tetraphosphonate (4iPO) and triphosphonate (3iPO) cavitand hosts used in this study were synthesized following the procedures developed by our group. ${ }^{33,34}$

\section{Silica supports}

Commercial aerosil silica $\left(200 \mathrm{~m}^{2} \mathrm{~g}^{-1}\right)$ was purchased from Degussa and used as received. SBA-15 mesoporous silica was prepared according to a procedure reported elsewhere. ${ }^{48-50}$ The ultra-large pore mesoporous silica (UL-SBA-15) was synthesized by adapting the following protocol described by Zhang et al. ${ }^{44}$ 
In a typical experiment, P123 (9.60 g, $1.65 \mathrm{mmol})$ was weighed into a Teflon bottle. Then, $1.07 \mathrm{M} \mathrm{HCl}(336 \mathrm{~mL}$, $360 \mathrm{mmol}$ ) was added and the mixture was stirred at room temperature until the P123 was fully dissolved. Decane $(76 \mathrm{~mL})$ was then added dropwise and after $1.5 \mathrm{~h}$ of stirring at room temperature, $\mathrm{NH}_{4} \mathrm{~F}(0.141 \mathrm{~g})$ and TEOS $(20.40 \mathrm{~g}, 97.92 \mathrm{mmol})$ were introduced. The reaction mixture was maintained at $40{ }^{\circ} \mathrm{C}$ for $20 \mathrm{~h}$ under vigorous stirring. Ageing was then carried out at $100{ }^{\circ} \mathrm{C}$ for a period of $48 \mathrm{~h}$. After cooling, the resulting solid was filtered and repeatedly rinsed with $1.07 \mathrm{M} \mathrm{HCl}$ and then $\mathrm{H}_{2} \mathrm{O}$. The white solid obtained was allowed to dry overnight at $50{ }^{\circ} \mathrm{C}$ and then was calcined in a muffle furnace $\left(5 \mathrm{~h}\right.$ at $\left.540{ }^{\circ} \mathrm{C}\right)$ to remove any trace of organic matter.

\section{Cavitand based hybrid material}

Synthesis of the azidopropyl functionalized silica. UL-SBA-15, a mesoporous silica containing azidopropyl groups, was prepared by using a post-synthetic grafting procedure. The silica material (4.60 g) was first activated under vacuum at $130{ }^{\circ} \mathrm{C}$ overnight. Dry toluene $(120 \mathrm{~mL})$ was then added under an argon atmosphere followed by 3-azidopropyltriethoxysilane (469.0 $\mathrm{mg}$ for a loading initially fixed at $0.40 \mathrm{mmol} \mathrm{g}^{-1}$ ). The mixture was stirred at room temperature for $3 \mathrm{~h}$ to allow for a better diffusion of the siloxane precursor inside the porous material, after which the temperature was increased and maintained at $90{ }^{\circ} \mathrm{C}$ for $48 \mathrm{~h}$. The resulting white solid was filtered, repeatedly rinsed with toluene and then subjected to Soxhlet extraction with methylene chloride for $8 \mathrm{~h}$. The solid was finally dried overnight at $50{ }^{\circ} \mathrm{C}$. The obtained material was denoted as $\left[\mathbf{N}_{3}\right] / \mathbf{U L}-\mathbf{S B A}-\mathbf{1 5}$.

Click of cavitand [3iPO] onto $\left[\mathbf{N}_{3}\right] / \mathrm{UL}-\mathrm{SBA}-15 .\left[\mathrm{N}_{3}\right] / \mathrm{UL}-\mathrm{SBA}-15$ $\left(1.1 \mathrm{~g}, 0.32 \mathrm{mmol}\right.$ of $\left.\left[\mathrm{N}_{3}\right]\right)$ was suspended in dry THF $(30 \mathrm{~mL})$ followed by addition of cavitand [3iPO] $(640.0 \mathrm{mg}, 0.413 \mathrm{mmol}$, $\sim 1.3$ eq.) dissolved in $3 \mathrm{~mL}$ of dry THF. The mixture was stirred for 1 hour at room temperature followed by addition of $\mathrm{N}, \mathrm{N}$ diisopropylethylamine (DIPEA) (266.8 mg, $2.064 \mathrm{mmol}, 6 \mathrm{eq}$.) and a catalytic amount of CuI. The mixture was stirred for $72 \mathrm{~h}$ at $30{ }^{\circ} \mathrm{C}$. The white solid obtained was filtered and repeatedly rinsed with THF and acetone. The white solid, referred to as [3iPO]/UL-SBA-15, was finally dried overnight at $40{ }^{\circ} \mathrm{C}$.

\section{Ammonium based hybrid materials}

In a typical experiment, the silica support ( $3 \mathrm{~g}$ ) was first activated under vacuum at $130{ }^{\circ} \mathrm{C}$ overnight to remove any trace of moisture. Then, dry acetonitrile $(80 \mathrm{~mL})$ was added under an argon atmosphere followed by $N$-[3-(trimethoxysilyl)propyl]$\mathrm{N}, \mathrm{N}, \mathrm{N}$-trimethylammonium chloride in solution in methanol (50 wt $\%, 335 \mu \mathrm{L}$ or $2.0 \mathrm{~mL}$ for an expected loading fixed at $0.2 \mathrm{mmol} \mathrm{g}^{-1}$ or $1.2 \mathrm{mmol} \mathrm{g}^{-1}$, respectively). The suspension was stirred for $3 \mathrm{~h}$ at room temperature to ensure dispersion of the ammonium precursor inside the pores, and then heated to $65{ }^{\circ} \mathrm{C}$ for $24 \mathrm{~h}$. The resultant white solid was isolated by filtration and repeatedly rinsed with acetonitrile before Soxhlet extraction with methylene chloride for $8 \mathrm{~h}$. The white solid was finally dried overnight at $50{ }^{\circ} \mathrm{C}$. The obtained materials were referred to as $\left[\mathbf{N}^{+}\right] / \mathbf{S B A}-\mathbf{1 5},\left[\mathbf{N}^{+}\right] / \mathbf{U L}-\mathbf{S B A}-\mathbf{1 5}$ and $\left[\mathbf{N}^{+}\right] / \mathbf{S i O}_{2}$ depending on the support used with the suffix LL or HL for low loaded $\left(\sim 0.2 \mathrm{mmol} \mathrm{g}^{-1}\right)$ or highly loaded $\left(\sim 1.2 \mathrm{mmol} \mathrm{g}^{-1}\right)$ catalysts, respectively.

\section{Characterization}

Small-angle X-ray powder diffraction (XRD) data were acquired on a Bruker D5005 diffractometer using $\mathrm{Cu} \mathrm{K} \alpha$ monochromatic radiation $(\lambda=1.5418 \AA$ ) . Nitrogen adsorption-desorption isotherms at $77 \mathrm{~K}$ were measured using a Micromeritics ASAP 2020M physisorption analyzer. The samples were evacuated at $10^{-5}$ Torr and $150{ }^{\circ} \mathrm{C}$ for $15 \mathrm{~h}$ before the measurements. The specific surface areas were calculated following the BET procedure. The pore size distribution was determined by using the $\mathrm{BJH}$ pore analysis applied to the desorption branch of the nitrogen adsorption-desorption isotherm. A Netzsch STA 409 PC thermoanalyser was used for simultaneous thermal analysis combining thermogravimetric analysis (TGA) and differential thermoanalysis (DTA) at a heating rate of $3{ }^{\circ} \mathrm{C} \mathrm{min}{ }^{-1}$ in air from $25-900{ }^{\circ} \mathrm{C}$. Solid state CP-MAS experiments were performed on Bruker Avance II 300 and Bruker Avance III $500 \mathrm{MHz}$ spectrometers using a $4 \mathrm{~mm}$ double resonance Bruker MAS probe at spectral frequencies of 75.5 and $59.6 \mathrm{MHz}$ for, respectively, ${ }^{13} \mathrm{C}$ and ${ }^{29} \mathrm{Si}$ nuclei with the $300 \mathrm{MHz}$ spectrometer and $202.4 \mathrm{MHz}$ for ${ }^{31} \mathrm{P}$ nucleus with the $500 \mathrm{MHz}$ spectrometer. The chemical shifts are referenced to TMS or external $85 \% \mathrm{H}_{3} \mathrm{PO}_{4}$. The spinning rate was $5 \mathrm{kHz}\left({ }^{29} \mathrm{Si}\right)$ or $10 \mathrm{kHz}\left({ }^{13} \mathrm{C}\right.$ and $\left.{ }^{31} \mathrm{P}\right)$ and the samples were spun at the magic angle (MAS) using $\mathrm{ZrO}_{2}$ rotors. The experimental details of the NMR experiments were as follows: contact time: $2 \mathrm{~ms}$, repetition time: $2 \mathrm{~s}$, number of scans: 3000 to 25000 depending on the loading and the nature of the sample. During catalytic testing, the yields and conversions were estimated by ${ }^{1} \mathrm{H}$ NMR on a Bruker Avance 300 spectrometer at $300.1 \mathrm{MHz}$ using 2,4-dibromomesitylene as an internal standard. $\mathrm{C}$ and $\mathrm{N}$ elemental analysis was performed by ICP-AES (Activa Jobin Yvon) spectroscopy from a solution obtained by treatment of the solid catalyst with a mixture of $\mathrm{HF}, \mathrm{HNO}_{3}$ and $\mathrm{H}_{2} \mathrm{SO}_{4}$ in a Teflon reactor at $150{ }^{\circ} \mathrm{C}$. Cl elemental analysis was performed by a combination of combustion and ionic chromatography. The samples were pyrolyzed at $1000{ }^{\circ} \mathrm{C}$ under an argon atmosphere and then oxidized with oxygen to obtain $\mathrm{Cl}_{2}$ and $\mathrm{HCl}$ species. These compounds were collected using a liquid absorbent and then analyzed by ionic chromatography. Fourier transform infrared spectra (FT-IR) were recorded from $\mathrm{KBr}$ pellets using a JASCO FT/IR-4200 (JASCO) spectrometer in the absorbance mode.

\section{Catalytic testing}

In a typical experiment, styrene oxide $(2.0 \mathrm{mmol})$, ammonium catalyst ( $2 \mathrm{~mol} \%$, soluble or grafted), cavitand co-catalyst ( $2 \mathrm{~mol} \%$, soluble or grafted), 2,4-dibromomesitylene (used as internal standard, $0.4 \mathrm{mmol}$ ) and methyl ethyl ketone $(6 \mathrm{~mL})$ were loaded into a $30 \mathrm{~mL}$ stainless autoclave. The reactor was flushed three times at room temperature with 5 bar of $\mathrm{CO}_{2}$ to remove air from the vessel before it was charged to 10 bar of $\mathrm{CO}_{2}$ and the temperature was increased to $80{ }^{\circ} \mathrm{C}$. After the desired reaction time, the reactor was cooled with an ice bath to stop the reaction and the excess amount of $\mathrm{CO}_{2}$ was carefully released. The crude mixture was recovered by centrifugation and the solid was washed with acetonitrile to remove any 
physisorbed molecules from the silica surface. This procedure was repeated three times and the supernatants were collected and combined with the crude mixture prior to ${ }^{1} \mathrm{H}$ NMR analysis. Experimental details regarding the loading and mass introduced for each immobilized system are summarized in Tables S4-S6 (ESI $\dagger$ ).

\section{Molecular mechanics simulations}

In this study, the crystalline structure of $\beta$-cristobalite (face (011)) was chosen as a model of hydroxylated silica. Different configurations of functionalized silica-crystal surfaces were constructed with varied site densities in order to match the experimental data. The molecular mechanics parameters used for optimizing the geometries are obtained from the work of Clark et $a l .{ }^{51}$ and were completed by the adjunction of the experimental structural values obtained from the crystallographic Cambridge Structural Database. ${ }^{52}$ The force field parameters for $\mathrm{C}_{\mathrm{ar}}-\mathrm{P}$ bond stretching were an equilibrium bond length of $1.82 \AA$ with a force constant of $600 \mathrm{kcal} \mathrm{mole}^{-1}$ Angstrom $^{-2}$. The valence angles for the $\mathrm{C}_{\mathrm{ar}}-\mathrm{C}_{\mathrm{ar}}-\mathrm{P}$ and $\mathrm{C}_{\mathrm{ar}}-\mathrm{P}-\mathrm{O}$ bonds were fixed to 120 and 109.5 degrees, respectively, with a scissoring force constant of $0.35 \mathrm{kcal}$ per mole per degrees ${ }^{2}$.

\section{Acknowledgements}

We gratefully acknowledge financial support from the Région Auvergne-Rhône-Alpes, France (ARC environment project).

\section{Notes and references}

1 M. Aresta, Carbon Dioxide as Chemical Feedstock, Wiley-VCH, Weinheim, 2010.

2 I. Omae, Catal. Today, 2006, 115, 33.

3 T. Sakakura, J.-C. Choi and H. Yasuda, Chem. Rev., 2007, 107, 2365.

4 M. North, R. Pasquale and C. Young, Green Chem., 2010, 12, 1514.

5 P. Pescarmona and M. Taherimehr, Catal. Sci. Technol., 2012, 2, 2169.

6 C. J. Whiteoak, A. Nova, F. Maseras and A. W. Kleij, ChemSusChem, 2012, 5, 2032.

7 H. Büttner, L. Longwitz, J. Steinbauer, C. Wulf and T. Werner, Top. Curr. Chem., 2017, 375, 1.

8 D. J. Darensbourg, Chem. Rev., 2007, 107, 2388.

9 J. H. Clements, Ind. Eng. Chem. Res., 2003, 42, 663.

10 B. Schäffner, F. Schäffner, S. P. Verevkin and A. Börner, Chem. Rev., 2010, 110, 4554.

11 M. Halmann, in Chemical Fixation of Carbon Dioxide: Methods for Recycling $\mathrm{CO}_{2}$ into Useful Products, ed. M. Halmann, CRC Press, Boca Raton, 1993.
12 J. Meléndez, M. North and R. Pasquale, Eur. J. Inorg. Chem., 2007, 3323.

13 C. J. Whiteoak, N. Kielland, V. Laserna, F. Castro-Gómez, E. Martin, E. C. Escuardo-Adán, C. Bo and A. W. Kleij, Chem. - Eur. J., 2014, 20, 2264.

14 T. Ema, Y. Miyazaki, S. Koyama, Y. Yano and T. Sakai, Chem. Commun., 2012, 48, 4489.

15 C. Martín, C. J. Whiteoak, E. Martin, M. Martínez Belmonte, E. C. Escudero-Adán and A. W. Kleij, Catal. Sci. Technol., 2014, 4, 1615.

16 J. A. Castro-Osma, K. J. Lamb and M. North, ACS Catal., 2016, 6, 5012.

17 V. Calo, A. Nacci, A. Monopoli and A. Fanizzi, Org. Lett., 2002, 4, 2561.

18 Z.-Z. Yang, L.-N. He, C.-X. Miao and S. Chanfreau, Adv. Synth. Catal., 2010, 352, 2233.

19 E. R. Pérez, M. Odnicki da Silva, V. C. Costa, U. P. RodriguesFilho and D. W. Franco, Tetrahedron Lett., 2002, 43, 4091.

20 Y. Tsutsumi, K. Yamakawa, M. Yoshida, T. Ema and T. Sakai, Org. Lett., 2010, 12, 5728.

21 Y.-M. Shen, W.-L. Duan and M. Shi, Adv. Catal., 2003, 345, 337.

22 M. E. Wilhelm, M. H. Anthofer, M. Cokoja, I. I. E. Markovits, W. A. Herrmann and F. E. Kühn, ChemSusChem, 2014, 7, 1357.

23 S. Sopeña, G. Fiorani, C. Martín and A. W. Kleij, ChemSusChem, 2015, 8, 3248.

24 J. Sun, L. Han, W. Cheng, J. Wang, X. Zhang and S. Zhang, ChemSusChem, 2011, 4, 502.

25 C. J. Whiteoak, A. Nova, F. Maseras and A. W. Kleij, ChemSusChem, 2012, 5, 2032.

26 L. Martinez-Rodriguez, J. Otalora Garmilla and A. W. Kleij, ChemSusChem, 2016, 9, 749.

27 S. Gennen, M. Alves, R. Mereau, T. Tassaing, B. Gilbert, C. Detrembleur, C. Jerome and B. Grignard, ChemSusChem, 2015, 8, 1845.

28 A. M. Hardman-Baldwin and A. M. Mattson, ChemSusChem, 2014, 7, 3275.

29 T. Werner and N. Tenhumberg, J. $\mathrm{CO}_{2}$ Util., 2014, 7, 39.

30 B. Chatelet, L. Joucla, J.-P. Dutasta, A. Martinez, K. C. Szeto and V. Dufaud, J. Am. Chem. Soc., 2013, 135, 5348.

31 B. Chatelet, E. Jeanneau, J.-P. Dutasta, V. Robert, A. Martinez and V. Dufaud, Catal. Commun., 2014, 52, 26.

32 B. Chatelet, L. Joucla, J.-P. Dutasta, A. Martinez and V. Dufaud, Chem. - Eur. J., 2014, 20, 8571.

33 A. Mirabaud, J.-C. Mulatier, A. Martinez, J.-P. Dutasta and V. Dufaud, ACS Catal., 2015, 5, 6748.

34 M. J.-C. Mulatier, A. Martinez, J.-P. Dutasta and V. Dufaud, Catal. Today, 2017, 281, 387.

35 R. A. Watile, K. M. Deshmukh, K. P. Dhake and B. M. Bhanage, Catal. Sci. Technol., 2012, 2, 1051.

36 K. Motokura, S. Itagaki, Y. Iwasawa, A. Miyaji and T. Baba, Green Chem., 2009, 11, 1876.

37 T. Sakai, Y. Tsutsumi and T. Ema, Green Chem., 2008, 10, 337.

38 T. Takahashi, T. Watahiki, S. Kitazume, H. Yasuda and T. Sakakura, Chem. Commun., 2006, 1664.

39 Y. Zhao, J.-S. Tian, X.-H. Qi, Z.-N. Han, Y.-Y. Zhuang and L.-N. He, J. Mol. Catal. A: Chem., 2007, 271, 284. 
40 Y. Du, J.-Q. Wang, J.-Y. Chen, F. Cai, J.-S. Tian, D.-L. Kong and L.-N. He, Tetrahedron Lett., 2006, 47, 1271.

41 S. Baj, T. Krawczyk, K. Jsiak, A. Siewniak and M. Pawlyta, Appl. Catal., A, 2014, 488, 96.

42 C. Kohrt and T. Werner, ChemSusChem, 2015, 8, 2031.

43 J. Steinbauer, L. Longwitz, M. Frank, J. Epping, U. Kragl and T. Werner, Green Chem., 2017, 19, 4435.

44 H. Zhang, J. Sun, D. Ma, X. Bao, A. Klein-Hoffmann, G. Weinberg, D. Su and R. Schlogl, J. Am. Chem. Soc., 2004, 126, 7440.

45 IUPAC Recommendations, Pure Appl. Chem., 1985, 57, 603.

46 V. Matsura, Y. Guari, J. Larionova, C. Guerin, A. Caneschi, C. Sangregorio, E. Lancelle-Beltran, A. Mehdi and R. J. P. Corriu, J. Mater. Chem., 2004, 14, 3026.
47 Z. Guo, A. Lei, Y. Zhang, Q. Xu, X. Xue, F. Zhanga and X. Liang, Chem. Commun., 2007, 2491.

48 D. Zhao, J. Feng, Q. Huo, N. Melosh, G. H. Fredrickson, B. F. Chmelka and G. D. Stucky, Science, 1998, 279, 548.

49 D. Zhao, Q. Huo, J. Feng, B. F. Chmelka and G. D. Stucky, J. Am. Chem. Soc., 1998, 120, 6024.

50 D. Zhao, J. Sun, Q. Li and G. D. Stucky, Chem. Mater., 2000, $12,275$.

51 M. Clark, R. D. Cramer and N. Van Opdenbosch, J. Comput. Chem., 1989, 10, 982.

52 The Cambridge Structural Database C. R. Groom, I. J. Bruno, M. P. Lightfoot and S. C. Ward, Acta Crystallogr., Sect. B: Struct. Sci., Cryst. Eng. Mater., 2016, 72, 171. 